\title{
Using Scanning Transmission Electron Microscopy (STEM) for Accurate Virus Dosing Quantification
}

Candace D Blancett, David P Fetterer, Keith A Koistinen, Elaine M Morazzani, Mitchell K Monninger, Ashley E Piper, Kathy A Kuehl, Pamela J Glass, Mei G Sun

US Army Medical Research Institute of Infectious Diseases, Ft. Detrick, MD, USA

Virus quantification is an important step to validate dosing in experimental challenges when characterizing an animal model of an infectious disease. Various biochemical assays and techniques including plaque assay, tunable resistive pulse sensing (TRPS), and quantitative polymerase chain reaction (qPCR) have been used for decades to fulfill this need. Different techniques provide different perspectives; however, due to their own technical limitations they frequently provide variable or even conflicting results with one another $[1,2]$. Transmission Electron Microscopy (TEM) is used to particle count for virus quantification but requires negative staining of the sample and labor intensive imaging and interpretation [3]. The distinct advantage of electron microscopy virus quantification is the ability to simultaneously distinguish intact virus from partial virus and note any abnormal viral morphology; however, its accuracy is always debated among experts [2]. Here, we propose a novel method utilizing scanning transmission electron microscopy (STEM) with simplified sample preparation, easy imaging using ATLAS software, and automatic data analysis with ImageJ software. This method improves data accuracy and provides results consistent with plaque assay.

Equal volumes of virus (unknown concentration) and nano-gold particles (known concentration) are distributed and adhered onto formvar-carbon coated 200-mesh copper EM grids using a capsule based microscopy processing system (mPrep System, Microscopy Innovations, LLC, WI) (Figure 1). BSL3/4 level viruses are inactivated by aldehyde fixation and exposure to osmium tetroxide fumes. Specimen images are acquired on a Zeiss Sigma Field emission SEM by STEM detector at $30 \mathrm{kV}$ with $4 \mathrm{~nm} / \mathrm{pixel}$ resolution, combined with Zeiss FIBICS ATLAS software. Image analysis and automatic enumeration of virus and gold particles is performed using ImageJ software. The relationship between the number of virus and nano-gold particles is used to calculate the virus concentration.

EM particle counting data from various virus stocks were compared with plaque assay (Figure 2). EM counts were consistently higher which was expected since EM is able to count all viral particles, whereas plaque assay can only count particles which are capable of infection. We do see consistent trends among the sampled virus where those with higher plaque assay concentrations also had higher EM particle counts, leading us to conclude our assay is accurate. For all of the VEEV, EEEV, and WEEV virus stocks the particle to pfu ratio ranged from 20-150. All ratio values were roughly equivalent, within a log of each other. These values were consistent with previous alphavirus studies with ratio values ranging from 20-2000 (Parker M., personal communication). [4]

\section{References:}

[1] Bettarel, Y. et al, Appl Environ Microbiol, 2000. 66(6): p. 2283.

[2] Rossi, C.A., et al, Viruses, 2015. 7(3): p. 857.

[3] Malenovska, H., J Virol Methods, 2013. 191(2): p. 136. 
[4] US Army Medical Research Institute of Infectious Disease (USAMRIID) Disclaimer: Opinions, interpretations, conclusions, and recommendations are those of the authors and are not necessarily endorsed by the U.S. Army.

(A)

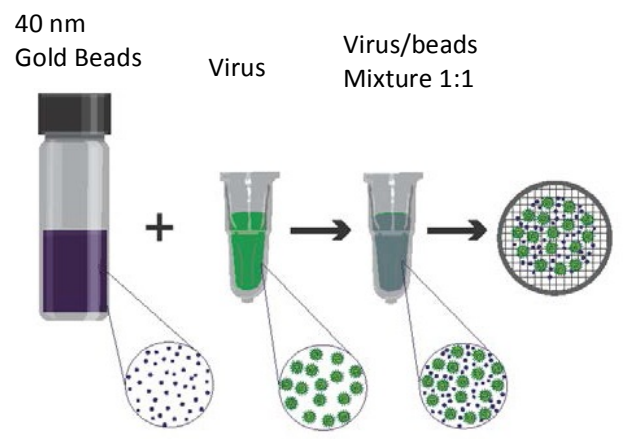

(B)

\author{
$\left(\frac{\text { Virus Particle }}{\text { Bead }}\right)_{\text {Solution }} \approx\left(\frac{\text { Virus Particle }}{\text { Bead }}\right)_{\text {Grid }}$ \\ $(\text { Virus Particle })_{\text {Solution }} \approx\left(\frac{\text { Virus Particle }}{\text { Bead }}\right)_{\text {Grld }}(\text { Bead })_{\text {Solution }}$
}

Figure 1: Experiment Overview (A) Illustration of the procedure: mixing known concentration of gold beads with unknown concentration of viral particles and applying the mixture to the EM grid for STEM imaging. (B) Formula for the calculation of unknown virus particles using the known concentration of gold beads and the virus-gold ratio.

\begin{tabular}{|c|c|c|c|}
\hline Virus Stock & $\begin{array}{c}\text { Plaque } \\
\text { Assay Titer } \\
\text { (pfu/ml) }\end{array}$ & $\begin{array}{c}\text { STEM Particle } \\
\text { Count } \\
\text { (particle/ml) }\end{array}$ & $\begin{array}{c}\text { Particle: } \\
\text { PFU } \\
\text { Ratio }\end{array}$ \\
\hline EEEV V105 Master Stock & $3.68 \mathrm{E}+08$ & $8.38 \mathrm{E}+09$ & 23 \\
\hline EEEV V105 Working Stock & $2.30 \mathrm{E}+09$ & $6.75 \mathrm{E}+10$ & 30 \\
\hline EEEV V105 Sucrose Purified & $2.20 \mathrm{E}+11$ & $6.60 \mathrm{E}+12$ & 30 \\
\hline VEEV 9813 Master stock & $6.35 \mathrm{E}+09$ & $3.23 \mathrm{E}+11$ & 51 \\
\hline VEEV 9813 Working stock & $3.00 \mathrm{E}+09$ & $3.27 \mathrm{E}+11$ & 109 \\
\hline VEEV 9813 Sucrose Purified & $3.55 \mathrm{E}+10$ & $4.52 \mathrm{E}+12$ & 127 \\
\hline WEEV McMilliam Master Stock & $3.50 \mathrm{E}+07$ & $1.11 \mathrm{E}+09$ & 32 \\
\hline WEEV McMilliam Working Stock & $1.90 \mathrm{E}+07$ & $1.05 \mathrm{E}+09$ & 55 \\
\hline WEEV Fleming pre-master Stock & $1.73 \mathrm{E}+08$ & $1.04 \mathrm{E}+10$ & 60 \\
\hline WEEV Fleming Master Stock & $1.78 \mathrm{E}+08$ & $9.63 \mathrm{E}+09$ & 54 \\
\hline
\end{tabular}

Figure 2: EM particle counting results for 10 different viruses are consistent with Plaque assay results, determining particle to PFU ration for dosing. STEM particle counts were completed for the Alphavirus Animal Model Program wild type virus stocks. Viral stocks were produced at USAMRIID by passage in ATCC Vero 76 cells. Master (Vero-2), Working (Vero-3) and sucrosepurified (Vero-4) stocks were prepared by infection of ATCC Vero cells with a multiplicity of infection of $0.5-1$. The titer $(\mathrm{pfu} / \mathrm{ml})$ of the virus stocks were determined by plaque assay. 